\title{
Study of right bundle-branch block in association with either left anterior hemiblock or left posterior hemiblock using His bundle electrograms
}

\author{
R. A. J. Spurrell, C. S. Smithen ${ }^{1}$, and Edgar Sowton \\ From the Department of Cardiology, Guy's Hospital, London
}

His bundle electrograms have been recorded in 4 patients with sinus rhythm, right bundle-branch block, and left anterior hemiblock, and in 2 patients with sinus rhythm, right bundle-branch block, and left posterior hemiblock. The findings of a long His- $Q$ interval in these patients suggest that there is more widespread involvement of the bundle-branches leading to trifascicular disease. All 6 patients gave a history of syncopal episodes and all subsequently developed intermittent or permanent complete heart block. It is suggested that the recording of His bundle electrograms in patients with bifascicular block is a useful technique for assessing conduction down the third remaining bundle-branch and if this is found to be impaired in patients with syncopal attacks this could constitute an indication for the implantation of a pacemaker.

The presence of complete right bundle-branch block in association with either left anterior hemiblock or left posterior hemiblock can be diagnosed from the external electrocardiogram (Pryor and Blount, 1966; Rosenbaum, 1968). When this occurs the sinus impulse is transmitted to the ventricles via one or other divisions of the left bundle, the anterior division if the posterior is blocked and the posterior division if the anterior is blocked. Should this remaining division of the left bundle also be diseased but not totally blocked then the conduction system is at risk, and should the remaining division become totally blocked, then complete heart block will develop. In the presence of bifascicular block, disease in the third remaining fascicle should be suspected in the presence of a long PR interval or the development of second-degree heart block (Rosenbaum et al., 1969). We have used the technique of recording His bundle electrograms (Scherlag et al., I969) to study patients with bifascicular block in order to assess the functional competence of the third remaining fascicle upon which ventricular activation is dependent.

Received Is November 1971.

1 Present address: Department of Cardiology, New York Hospital, Cornell Medical Centre, New York City, U.S.A.

\section{Patients and methods}

Six male patients were studied; all gave a history of syncopal episodes but when first seen the patients were in sinus rhythm. None of the patients was taking digoxin or diuretics when studied. The details of the patients and their electrocardiograms are shown in Table $\mathrm{r}$.

All 6 patients had right bundle-branch block. In addition, 4 patients (Cases I, 2, 3, 5) had left anterior hemiblock and 2 patients (Cases 4 and 6 ) had left posterior hemiblock. (Right ventricular hypertrophy was excluded in these 2 patients.)

In each patient a His bundle recording was obtained. A bipolar catheter was introduced into a femoral vein by direct puncture and passed to the right ventricle under fluoroscopic control. A second bipolar catheter was passed to the right atrium via a brachial vein; this was connected to a Multitone external pacemaker and used for atrial pacing. The catheter in the right ventricle was connected to the electrocardiograph input of a Cambridge photographic recorder and in one patient to a Mingograph 34. Records were taken with the frequency response set at $80-500$ cycles/ $\mathrm{sec}$ and at a paper speed of $100 \mathrm{~mm} / \mathrm{sec}$. An external electrocardiogram was recorded simultaneously. The catheter in the right ventricle was withdrawn across the tricuspid valve until the bior triphasic spike of the His potential was seen between the $P$ wave and the QRS complex of the external electrocardiogram. Bipolar and unipolar recordings were obtained. Recordings were taken while in sinus rhythm and during atrial pacing up 
TABLE I Details of electrocardiograms taken while patients were in sinus rhythm

\begin{tabular}{llllllll}
\hline Patient & $\begin{array}{c}\text { Age } \\
(y r)\end{array}$ & Sex & PR interval & $\begin{array}{l}\text { Mean frontal } \\
\text { plane QRS axis }\end{array}$ & $\begin{array}{l}\text { Bundle-branch } \\
\text { block }\end{array}$ & $\begin{array}{c}\text { QRS } \\
\text { width }\end{array}$ & Complete heart block \\
\hline I & 76 & M & 0.22 & $-70^{\circ}$ & RBBB & 0.14 & Seen on oscilloscope \\
2 & 85 & M & 0.20 & $-90^{\circ}$ & RBBB & 0.16 & Seen on oscilloscope \\
3 & 62 & M & 0.17 & $-60^{\circ}$ & RBBB & 0.13 & Electrocardiogram obtained \\
4 & 76 & M & 0.22 & $+120^{\circ}$ & RBBB & 0.12 & Seen on oscilloscope \\
5 & 85 & M & 0.20 & $-40^{\circ}$ & RBBB & 0.14 & Electrocardiogram obtained \\
16 & 75 & M & 0.24 & $+120^{\circ}$ & RBBB & 0.14 & Electrocardiogram obtained \\
\hline
\end{tabular}

RBBB - right bundle-branch block.

TABLE 2 Results obtained from His bundle electrograms

\begin{tabular}{lllllll}
\hline Case No. & $\begin{array}{l}\text { P-His } \\
\text { sinus rhythm }\end{array}$ & $\begin{array}{l}\text { ST-His } \\
\text { atrial pacing }\end{array}$ & His- $Q$ & $\begin{array}{l}\text { RR } \\
\text { interval }\end{array}$ & Rate/min & His bundle pacing \\
\hline I & 139 & & 72 & 775 & 78 & RBBB pattern persists \\
& & 185 & 72 & 610 & 99 & \\
2 & 204 & 78 & 465 & 130 & RBBB pattern persists \\
& 120 & 130 & 98 & 600 & 100 & \\
& & 145 & 104 & 598 & 102 & \\
3 & & 150 & 100 & 510 & 119 & RBBB pattern persists \\
& & & 670 & 130 & RBBB pattern persists \\
4 & 140 & 220 & 65 & 670 & 68 & His bundle not captured \\
5 & 128 & - & 99 & 690 & 100 & \\
& 120 & & 71 & 910 & 65 & RBBB pattern persists \\
\hline
\end{tabular}

RBBB, right bundle-branch block.

to a rate of $160 / \mathrm{min}$. Finally in each patient the His bundle was paced using the bipolar catheter placed in the region of the His bundle and connecting it to a Multitone external pacemaker. His bundle pacing was carried out up to a rate of $160 / \mathrm{min}$. The following measurements were made from the records obtained.

P-His - the time in milliseconds between the onset of the $P$ wave on the external electrocardiogram and the first deflection of His deflection on the intracardiac recording.

$S T$-His - the time in milliseconds between the atrial pacing stimulus as seen on the external electrocardiogram and the onset of the His deflection as seen on the intracardiac recording.

His- $Q \quad$ - the time in milliseconds between the onset of the His deflection and the onset of the QRS complex on the external electrocardiogram.

$R R$ interval - the time in milliseconds between two successive $\mathbf{R}$ waves on the external electrocardiogram.

The normal P-His interval was taken as $80-140$ msec for heart rates below $80 / \mathrm{min}$. The normal
FIG. I Electrocardiogram from Case I.

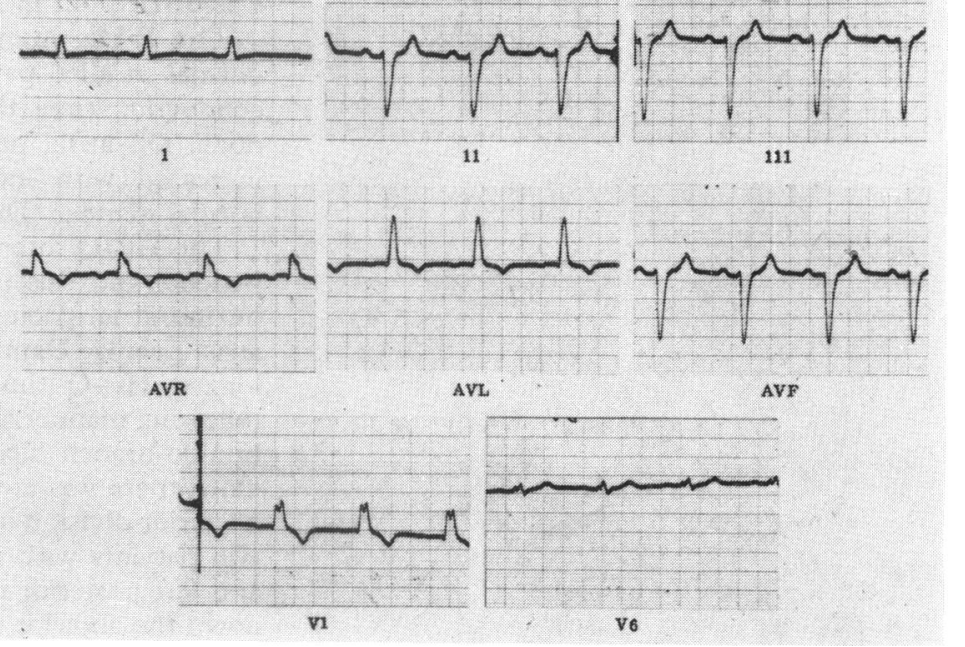




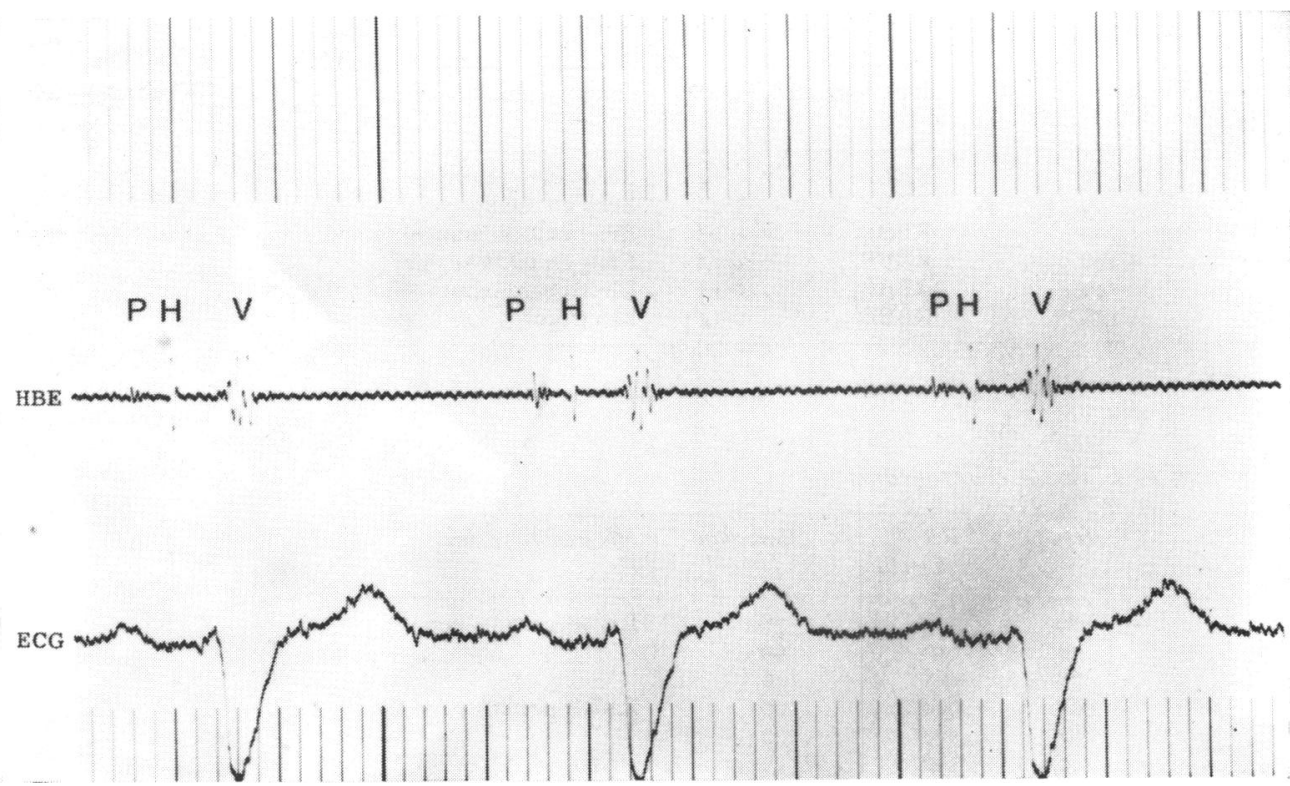

FIG. 2 His bundle electrogram from Case I recorded during sinus rhythm. HBE, His bundle electrogram; $P$, atrial depolarization; $H$, His bundle depolarization; $V$, ventricular depolarization.

FIG. 3 His bundle electrogram from Case I recorded during atrial pacing at a rate of I30/min. ST, pacing stimulus artefact.

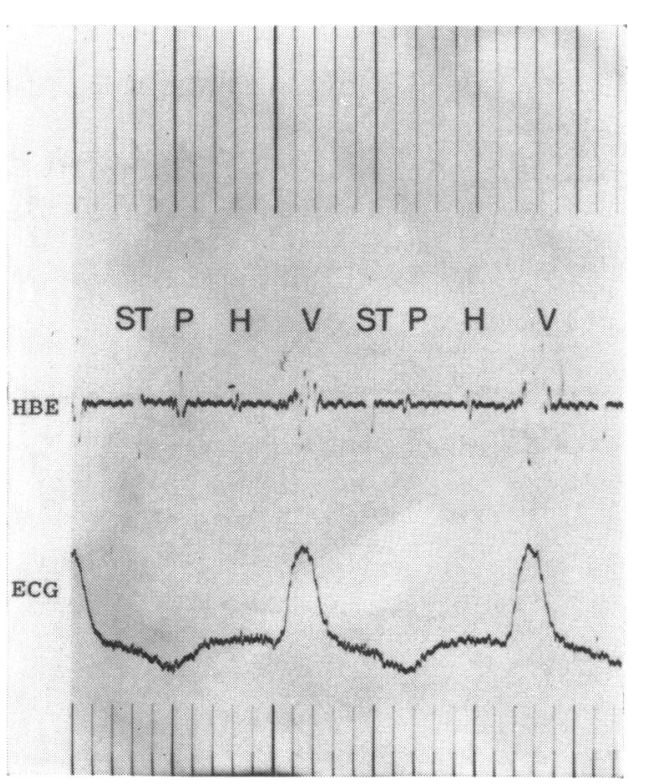

His- $Q$ interval was taken as $42-60 \mathrm{msec}$. These figures are based upon unpublished data of our own confirming reported values from Damato $e t$ al. (1969).

The results of the His bundle electrograms are shown in Table 2. Fig. I-8 are His bundle recordings from Cases $I$ and 2 and are explained in the text.

\section{Results}

His bundle electrograms The His bundle was recorded in all 6 patients and atrial pacing was carried out in 4 (Cases $1,2,3,5$ ).

The P-His interval in sinus rhythm was normal in all 6 patients indicating a normal conduction time through the atria and $\mathrm{AV}$ node. On atrial pacing the ST-His interval increased with increasing heart rates in a normal manner (Damato et al., 1969).

The His-Q interval was prolonged in all 6 patients and this interval remained constant during atrial pacing (the normal response to atrial pacing, Damato et al., 1969). The prolonged His- $Q$ time was interpreted in the following manner. In the 4 patients with right bundle-branch block and left anterior hemiblock there was a conduction delay down the posterior division of the left bundle and in the two patients with right bundle-branch block and left posterior hemiblock there was delay down the anterior division of the left bundle. 


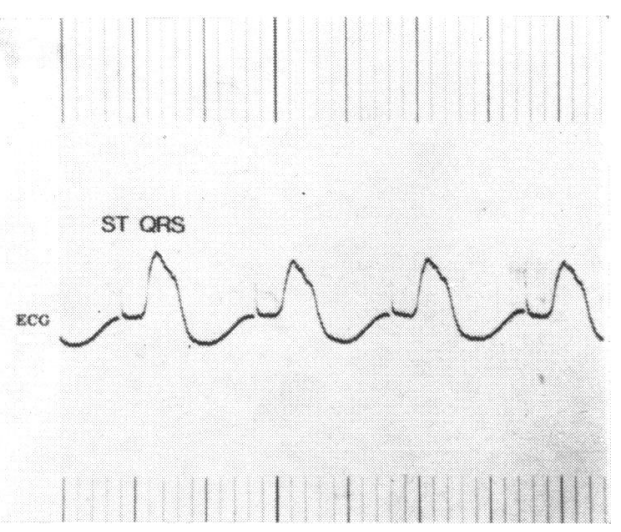

FIG. 4 External electrocardiogram (lead I) in Case I recorded during His bundle pacing at a rate of $160 / \mathrm{min}$. Note persistence of right bundle-branch block pattern.

The His bundle was successfully paced in 5 patients, but in one (Case 5) this was unsuccessful. In all 5 patients the right bundlebranch block pattern persisted during His bundle pacing.

All 6 patients went into complete heart block while in hospital, verified either on an oscilloscope or by an electrocardiogram recording, and all 6 patients required a permanent implanted pacemaker.

\section{Discussion}

Conduction of the sinus node impulse to the ventricles in man takes place via the AV node, the bundle of His, and from the bundle of His it passes to the right ventricle via the right bundle-branch and to the left ventricle via the anterior and posterior divisions of the left main bundle. Complete block in either the right bundle or the left bundle can be diagnosed satisfactorily from the external electrocardiogram. Block in the anterior or posterior division of the left bundle, either isolated or in association with right bundle branch-block, can be diagnosed from the external electrocardiogram by analysis of the initial and terminal QRS vectors in the frontal plane. In left anterior hemiblock the initial QRS vector passes inferiorly and to the left and the terminal QRS vector passes superiorly and leftward resulting in a small $Q$ wave in lead aVL followed by a tall $R$ wave, and a small $R$ wave in lead III followed by a deep $S$ wave, the resulting mean frontal plane axis being greater than $-30^{\circ}$. In left posterior hemiblock the initial vector passes leftward and superiorly and produces a small $R$ wave in lead $I$ and a small $Q$ wave in lead III and the terminal vector passes inferiorly and produces a deep $S$ wave in lead I and a tall $R$ wave in lead III, resulting in a mean frontal plane QRS axis of $+120^{\circ}$ or greater (Pryor and Blount, 1966; Rosenbaum, 1968, 1969). If in the presence of bifascicular block, first-degree or second-degree heart block is present this could be interpreted as showing either added delay of conduction between the sinus node and the bundle of His or delay down the third fascicle. Three of our patients with bifascicular block had long PR intervals suggesting delay in conduction down the third fascicle, and this was verified by the finding of a long His- $Q$ interval. The other 3 patients showed bifascicular block only and no other evidence of conduction delay; however, the His bundle electrogram in these patients showed a long His- $Q$ interval demonstrating further conduction delay down the third fascicle and therefore trifascicular disease.

The 2 patients with right bundle-branch block and left posterior hemiblock both had long PR intervals suggesting further conduction delay down the anterior division of the left bundle; this was confirmed by the long His- $Q$ interval. Patients with right bundlebranch block and left posterior hemiblock are likely to have associated disease of the anterior division of the left bundle, the reason for this being that the posterior division is the least vulnerable fascicle and if diseased it suggests

\section{FIG. 5 External electrocardiogram from}

Case 2.

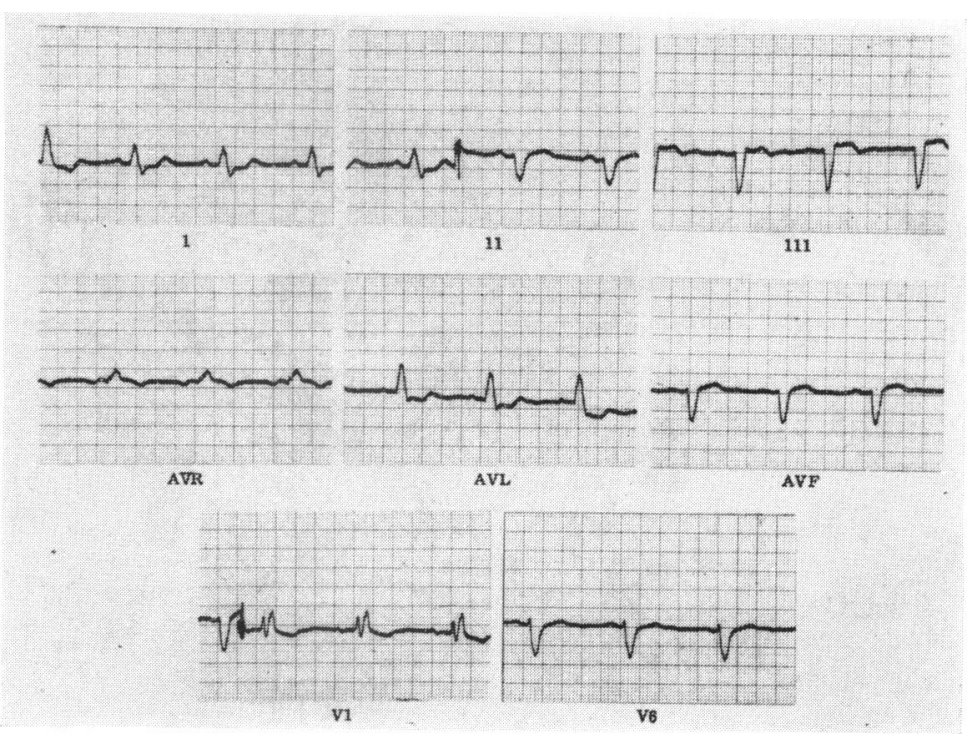




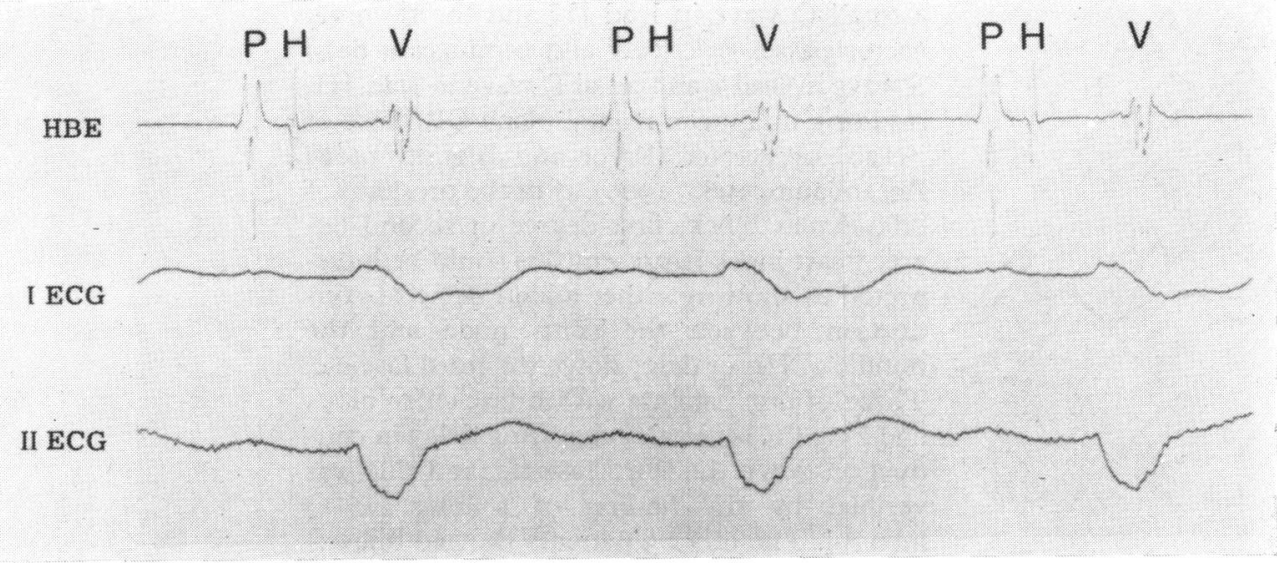

FIG. 6 His bundle electrogram from Case 2 during sinus rhythm.

that there may be more widespread lesions involving the right bundle and the anterior division of the left bundle in addition. This is further borne out by the statement that 75 per cent of patients with right bundle-branch block and left posterior hemiblock go into complete heart block, whereas only 17 per cent of patients with right bundle-branch block and left anterior hemiblock go into complete heart block (Rosenbaum, I968). Of the 4 patients with right bundle-branch block and left anterior hemiblock, only one patient had evidence of trifascicular disease as evidenced by a long PR interval. The remaining 3 patients had evidence of bifascicular block only, but the His bundle electrogram showed them all to have long His- $Q$ intervals thereby demonstrating the presence of trifascicular disease.

The history of syncopal episodes in patients with right bundle-branch block and either left anterior hemiblock or left posterior hemiblock strongly suggests that intermittent complete heart block is occurring even though the

FIG. 7 His bundle electrogram from Case 2 recorded during atrial pacing at a rate of 130/min.

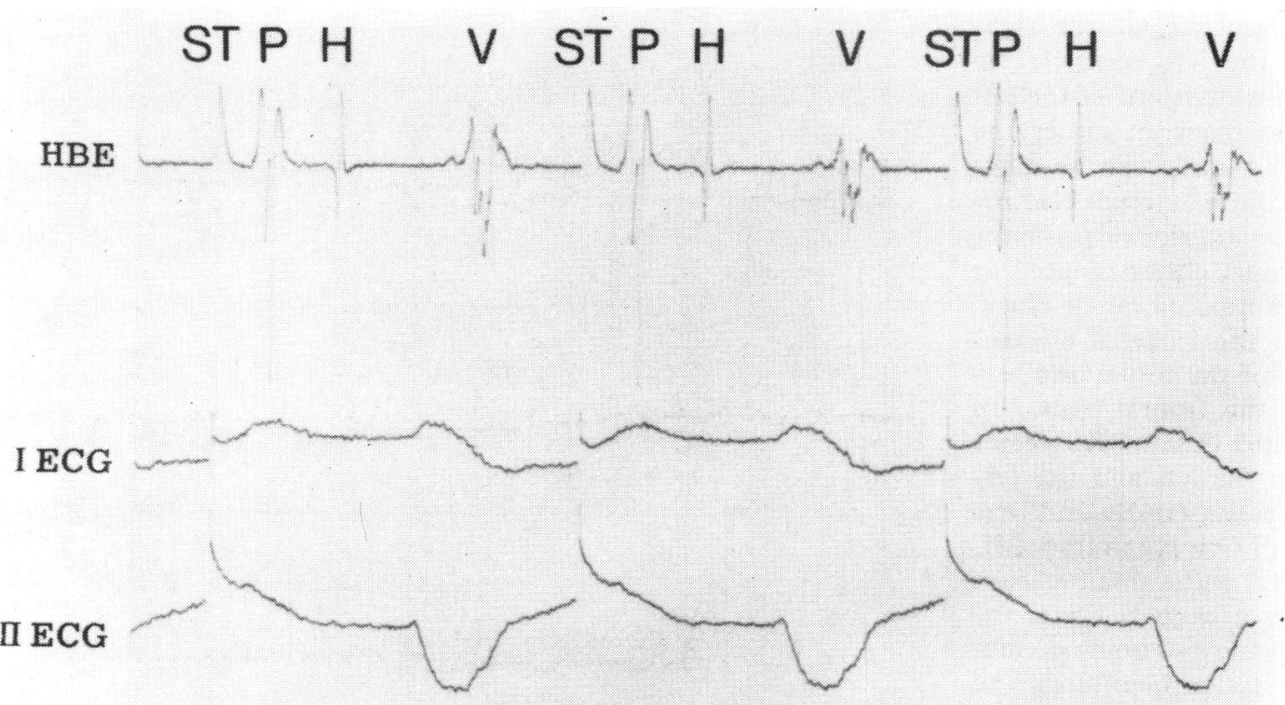



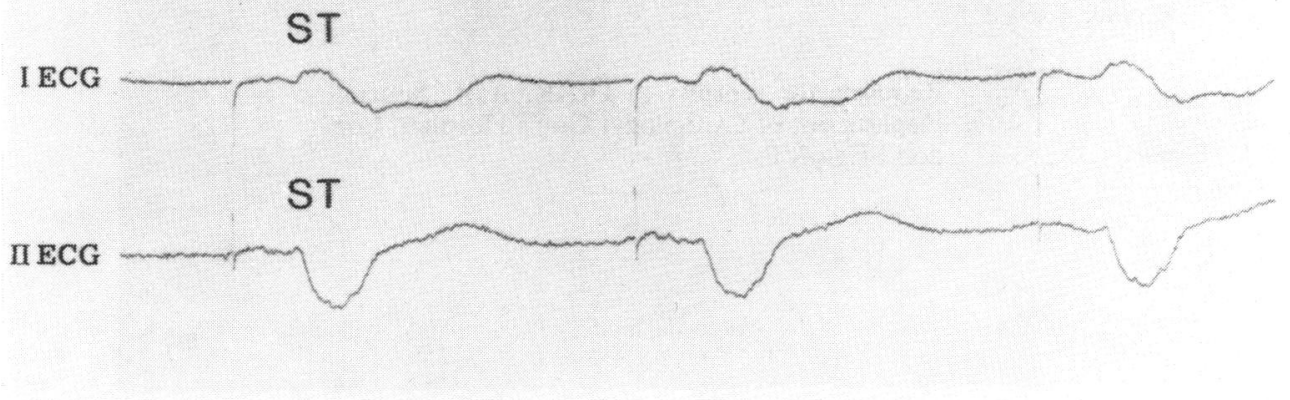

FIG. 8 External electrocardiogram (leads I and II) recorded from Case 2 during His bundle pacing at a rate of $102 / \mathrm{min}$.

electrocardiogram shows sinus rhythm when the patient is first seen. Kulbertus and Collignon (1969) followed 16 patients with right bundle-branch block and either left anterior hemiblock or left posterior hemiblock. All I6 patients gave a history of syncopal episodes and all 16 patients subsequently developed transient or permanent complete heart block. The 6 patients in our study all showed bifascicular block on their cardiograms, all had a history of syncopal episodes, and all subsequently developed complete heart block. By recording the His bundle electrogram we were able to show that in this group of patients evidence of trifascicular disease was present while in sinus rhythm and therefore the risk of developing complete heart block was present. It is interesting that in 12 patients studied by Haft et al. (197I) by recording His bundle electrograms, I I patients had normal His- $Q$ intervals and I patient had a prolonged His-Q interval. None of the 12 patients had a history of syncopal episodes and complete heart block had not been recorded.

His bundle pacing is carried out in order to verify that the deflection seen on the intracardiac recording between the $P$ wave and the QRS complex is the His deflection and not the right bundle-branch potential or part of the QRS complex. If the His bundle is paced, then there will be no change in form of the QRS complex on the external electrocardiogram. If the right bundle-branch or part of the ventricle is paced, then the QRS complex on the external electrocardiogram will take on a left bundle-branch block pattern (Narula, Scherlag, and Samet, 1970). In this study pacing in the region of the His bundle was successfully carried out in 5 patients and the right bundle-branch block pattern persisted in all 5 patients, indicating that the deflection seen on the intracardiac recording was likely to be the His bundle and not the right bundle-branch potential.

We consider that the recording of a His bundle electrogram in patients with evidence of bifascicular block on their electrocardiograms and particularly in patients with a history of syncopal episodes is a valuable method for assessing conduction down the third remaining fascicle. Should the conduction be found to be delayed in this fascicle (as evidenced by the prolonged His- $Q$ interval), then a case can be made for the insertion of a pacemaker at that time despite the presence of sinus rhythm. A history of syncopal episodes is a strong additional feature in favour of pacemaker implantation.

\section{References}

Damato, A. N., Lau, S. H., Helfant, R. H., Stein, E., Berkowitz, W. D., and Cohen, S. I. (I969). Study of atrioventricular conduction in man using electrode catheter recordings of His bundle activity. Circulation, 39, 287.

Haft, J. I., Weinstock, M., DeGuia, R., Gupta, P. K., and Fano, A. (197I). Assessment of atrioventricular conduction in left and right bundle-branch block using His bundle electrograms and atrial pacing. American fournal of Cardiology, 27, 474.

Kulbertus, H., and Collignon, P. (1969). Association of right bundle-branch block with left superior or inferior intraventricular block. British Heart fournal, 31, 435 . 
Narula, O. S., Scherlag, B. J., and Samet, P. (1970). Pervenous pacing of the specialised conducting system in man. Circulation, 41, 77.

Pryor, R., and Blount, S. G., Jr. (1966). The clinical significance of true left axis deviation. American Heart fournal, 72, 391.

Rosenbaum, M. B. (1968). Types of right bundlebranch block and their clinical significance. fournal of Electrocardiology, 1, 22 I.

Rosenbaum, M. B. (1969). Types of left bundle-branch block and their clinical significance. fournal of Electrocardiology, 2, 197.

Rosenbaum, M. B., Elizari, M. V., Lazzari, J. O., Nau,
G. J., Levi, R. J., and Halpern, M. S. (1969). Intraventricular trifascicular blocks. American Heart Fournal, 78, 451 .

Scherlag, B. J., Lau, S. H., Helfant, R. H., Berkowitz, W. D., Stein, E., and Damato, A. N. (I969). Catheter technique for recording His bundle activity in man. Circulation, 39, 13.

Requests for reprints to Dr. R. A. J. Spurrell, Department of Cardiology, Guy's Hospital, London SEI 9RT. 